\title{
AS POLITTICAS SOCIAIS E DE SAÚDE NO BRASIL: UMA ABORDAGEM HISTÓRICA
}

Maria Amélia de Campos Oliveira *

OLIVEIRA, M.A de C. As políticas sociais e de saúde no Brasil: uma abordagem histórica. Rev. Esc. Enf. USP. v. 26, n. 1, p. 95-104, mar. 1992

A autora faz uma retomada histórica das políticas sociais e de saúde no Brasil, procurando correlacioná-las com as transformaçōes no modo de produção de cada período histórico. Busca evidenciar que as políticas sociais representam a administração, através do Estado, dos conflitos de classe e que as políticas de saúde espressam a desigualdade social, ma. nifesta no acesso diferenciado aos serviços de assistência à saúde.

UNITERMOS: Políticas sociais. Politicas de saúde.

\section{INTRODUÇÃO}

Nesta retomada histórica, procurar-se-á evidenciar como as políticas sociais emanadas do Estado brasileiro buscam cooptar as classes trabalhadoras para um projeto de classe que não lhes é próprio e que visa, em última instância, a acumulação do capital, questão inicialmente abordada em trabalho anteriors. A matriz que reproduz o modo de produção capitalista necessita repetir e renovar a força de trabalho do proletariado para garantir a execução das tarefas de acumulação a que se propõe. As políticas sociais representam a "administração", através do Estado, dos conflitos gerados pelo enfrentamento dos grupos sociais sem que se altere a estrutura de classes que propicia a existência deste modo de produção.

\section{HISTÓRICO DAS POLÍTICAS SOCIAIS NO BRASIL}

No Brasil-colônia, a economia nacional estava atrelada ao capitalismo liberal ou concorrencial europeu. Sua exploração se realizou em ciclos, sendo os principais os da cana-de-açucar, da mineração e do café, sendo que este último se prolongou pelo Império até a Repúbica. As relações de trabalho que se estabeleceram em cada um deles vão determinar a forma como se estruturaram as con-

\footnotetext{
- Enfermeira. Professora Assistente do Departamento de Enfermagem Preventiva e Comunitária da Escola de Enfermagem da Universidade de Sảo Paulo.
} 
dições de vida e de saúde da população nesses diversos períodos históricos. Tanto o é que, no período colonial, se obseva que a Saúde Pública estava voltada, inicialmente, para as campanhas de urbanização e de saneamento dos portos, com vistas a garantir a circulação e comercialização dos alimentos e produtos em direção à Metrópole ${ }^{2.0 .8}$.

No ciclo do açucar, que vai da segunda metade do século XVI até o final do século XVII, a exploração colonial se deu através da grande propriedade monocultora ou latifúndio e das relações de trabalho polarizadas entre o proprietário rural e seus escravos. A esta altura, o escravismo era perfeitamente adequado às exigências do capitalismo internacional da época e foi fundamental para realizar a acumulação de capitais ${ }^{7,8}$.

Durante todo o século XVIII, desenvolveu-se o ciclo da mineração, que viu surgir os setores sociais intermediários, como consequiência das novas necessidades de uma população que se dispersara para as regiōes de garimpo. Os produtores dos bens de subsistência concentraram-se em áreas urbanas próximas às das minerações, juntamente com o aparato administrativo que se criara para o controle e fiscalização da produção das minas. Desta forma se processaram tanto a interiorização quanto a urbanização, além de um crescimento demográfico acentuado ocasionado pela menor concentração da renda que este ciclo acarretou e também pela chegada de portugueses em busca do ouro. São essas camadas sociais intermediárias, que surgiram para suprir a demanda das populaçōes urbanas que, juntamente com a recém-criada burocracia do Estado, vão servir de arcabouço para a estrutura de classes que se irá encontrar no ciclo cafeeiro 6 .

No âmbito da saúde, as populaçōes de então utilizavam-se dos conhecimentos da medicina popular que resultaram dos sincretismo das práticas curativas dos índios, dos escravos e dos europeus. Somente os abastados proprietários rurais podiam custear a assistência dos raros médicos existentes no período colonial ${ }^{2.6}$. GERMANO² afirma que a prática médica deste período estava voltada para a cura das doenças e não para a sua prevenção. A prática de enfermagem era exercida nas Santas Casas de Misericórdia, cuja direção e manutenção ficava a cargo das ordens religiosas que chegavam.ao Brasil.

Rompido o monopólio comercial com a Metrópole após a Independência em 1822, a economia nacional voltou-se relativamente para o mercado interno, ainda que mantivesse a sua subordinação ao capital estrangeiro, dependente que era da importância dos produtos industrializados da Inglaterra. Iniciado no século XIX, o ciclo do café alcançou seu auge na segunda década deste, principalmente na região sudeste do país. $\mathrm{A}$ independência política não modificou as relações sociais de produção, emperradas tanto pela ausência de uma tecnologia própria, como pela falta do capital interno que se evadira para Portugal em conseqüência das atividades predatórias do colonialismo 6 .

Na primeira metade do século XIX esboçava-se certa organização em termos de saúde, visando conter as epidemias, principalmente de febre amarela, que assolavam a cidade do Rio de Janeiro. Articulou-se, então, um órgão dirigente para a Saúde Pública, com a responsabilidade sobre medidas sanitárias, além da fiscalização do exercício da medicina, cirurgia e farmácia ${ }^{2}$.

No final do século XIX, a burguesia cafeeira, como fração de classe econo- 
micamente dominante, tentou conciliar seus interesses com os da Monarquia. Não o conseguindo, sublevou-se e uniu-se ao movimento republicano que culminou com a proclamação da República em 1889. Esta fato marcou "a tomada do poder nacional por uma burguesia nascida do expansionismo econômico da riquesa cafeeira"'. A aristocracia rural foi substituída a partir daí pelo setor empresarial cafeeiro que ascendeu ao poder como um governo burguês oligárquico ${ }^{6}$.

A ação do Estado se fez sentir através de campanhas de erradicação da febre amarela e da peste bubônica, desenvolvidas pelo médico sanitarista Oswaldo Cruz durante o governo Rodrigues Alves (1902-1906). Estas cruzadas contra a doença deixaram como saldo a legitimação da ação do Estado e sua influência na saúde coletiva.

No tocante às ações individuais de saúde, estas continuavam ser restritas aos médicos que monopolizavam a arte de curar sob o respaldo da constituição de 1891, ainda que suas ações visassem atender apenas aos mais abastados. Aos demais estratos da população restava o atendimento das Santas Casas de Misericórdia e dos práticos da medicina popular. Para os trabalhadores ligados aos serviços básicos que permitiam a circulação e a exportação do café, iniciava-se um atendimento através de Caixas Beneficentes organizadas pelas próprias empresas que os contratavam, no caso, portuárias e ferroviárias, em sua maioria ${ }^{6,}$ ?

Se a prática médica do período em questão estava quase totalmente desvinculada das ações de higiene sanitária, a da enfermagem profissional surge atrelada à Saúde Pública. A Escola de Enfermagem Ana Néri, considerada efetivamente a primeira do país, nasceu em 1923, vinculada ao Departamento Nacional de Saúde Pública ${ }^{2.8}$.

ALBUQUERQUE ${ }^{1}$, argumenta que o novo modo de produzir a vida material que a industrialização traz, gera como consequüência novas necessidades para a classe trabalhadora. Esta, para reproduzir (renovar e repetir) sua força de trabalho, necessita de condições mínimas que se manifestam nas reivindicações por melhores condições de trabalho, diminuição da jornada diária, férias remuneradas e outras, além da questão da saúde. Esse enfrentamento de classes vai exigir que o Estado, na sua função mediadora, intervenha de forma cada vez mais acentuada para diminuir as tensōes sociais e perpetuar as relações sociais vigentes, sem alterar o processo de acumulação.

Em 1903, o Estado aceitou a idéia de que "agrupamentos sociais reunidos por interesse comum, pudessem ser admitidos como interlocutores no debate social...". Porém o ingresso da classe operária no cenário político, “...provocou importante fissura na ordem juridico-institucional laissez-fairiana, stricto sensu, ao admitir a legitimidade de demandas coletivas, antes que estritamente individuais" ". Para esse autor, essa ruptura marca o ingresso do sindicalismo na arena dos debates políticos brasileiros. Das reivindicaçōes sindicais, no entanto, somente se conseguiu a aprovação, em 1919, do decreto-lei que determinou a responsabilidade do empregador pelos acidentes ocorridos no trabalho. Excetuavamse os casos de incompetência ou negligência por parte do trabalhador, ressalva que favoreceu o não comprimento da lei na prática.

Somente em 1923, com a Lei Eloy Chaves, se reabriu outro período de regulamentação pelo Estado do problema social no país. Esta lei formulou as bases 
para a organização das Caixas de Aposentadorias e Pensões (CAPs) que manipulavam os fundos advindos do convênio particular feito entre empregadores e empregados para tratar questōes previdenciárias. Com o aumento dos recursos financeiros que esses fundos manipulavam, a gerência dessas CAPs passou a se constituir em importante elementos de poder político, tanto que o Estado lançou mão delas criando o Instituto Nacional de Previdência Social (INPS) em 1966. Sua criação representou um avanço em termos organizacionais e administrativos, por unificar as instituições previdenciárias, mas seu efeito colateral foi o afastamento tanto do empresário quanto do trabalhador do cenário decisório das políticas sociais, com o fortalecimento da burocracia do Estado?

Retornando ao que representou a Lei Eloy Chaves do ponto de vista das conquistas sociais do operariado, tem-se que somente a partir do início da legislação social, via CAPs, o Estado deu alguma atenção às antigas reivindicações sindicais. Até então, elas só haviam obtido como respostas a lei sobre acidentes do trabalho, de 1919; o decreto sobre as férias, de 1927 e o código que regulamentou o trabalho do menor, de 1929. A partir deste início, foram regulados outros ítens importantes do processo de produção, tais como a jornada de trabalho para comerciários e industriários, fixada em 8 horas diárias, a partir de 1932. No mesmo ano, disciplinou-se o trabalho feminino, estinguindo-se por lei (e somente na lei) a distinção salarial em função do sexo. Para a viabilização de tais medidas contava-se com Ministério do Trabalho, criando em 1931 e com a obrigatoriedade da carteira profissional para os trabalhadores urbanos, de $1932^{7}$.

Em 1923, com a Reforma Carlos Chagas, o rol dos beneficios providenciários principiou a incluir a assistência médica, ainda que esta lei contemplasse, em primeiro plano, as doenças de massa relacionadas ao processo de urbanização, como a malária, esquistossomose e verminose. Essa reforma "...viria oficializar uma primeira organização a nivel das prioridades em atenção médica, tornando possivel a expansão estatal dos serviços de atenção médica curativa a população"'. Com ela, foi criado o Departamento Nacional de Saúde Pública, tendo por atribuições o saneamento rural e urbano, a propaganda sanitária, a higiene materno-infantil, industrial e profissional, a fiscalização e supervisão da saúde e o combate as endemias.

Nesse momento, o endividamento externo consequente à economia agro-exportadora do ciclo do café agravara a crise social, porque a hegemonia dos interesses cafeeiros criara obstáculos ao desenvolvimento do mercado interno, A crise econômica mundial, ao alcançar seu vértice em 1929, desferiu um golpe fatal sobre a oligarquia rural brasileira, que foi forçada a ceder seu espaço político aos interesses da nova burguesia industrial e comercial. Aliada aos setores trabalhistas, esta nova fração de classe pressionou a adaptação do sistema produtivo a uma base urbano-industrial. A ruptura com o poder oligárquico e a emergência de um desenvolvimento capitalista menos atrelado aos centros hegemônicos mundiais gerou um nacionalismo que foi buscar respaldo nas classes trabalhadoras. Essa aliança, porém, revelou-se excludente no plano político, pois logo se realizou entre as antigas oligarquias rurais e a nova burguesia ascendente, um novo pacto social que preservou a antiga estrutura de classes. A revolução de 30 marcou essa ruptura com a antiga estrutura de poder e a entrada das massas populares urbanas no cenário político brasileiro ${ }^{6}$. 
O período de 1934 a 1940 caracterizou-se pelo progresso industrial gerado pela oferta abundante de mão-de-obra nas regiões urbanas, consequência da migração das populações rurais para as cidades. Esse mesmo crescimento industrial desenfreado e a concentração de capital favorecida por um salário mínimo fixado pelo Estado nos limites da subsistência da classe operária, levaram à deterioração das condiçōes de vida desta, com consequentes reflexos sobre a saúde. $O$ Estado, otimista com o acúmulo de capital advindo da industrialização, havia empreendido obras públicas que demandaram vultosos investimentos. Consequiência dessa somatória de fatores, surgira novamente a inflação. $O$ proletariado foi, então, mais uma vez penalizado pois “...em períodos de inflação (...) são os assalariados que mais são afetados, pois a inflação opera sempre transferindo renda deste grupo aos empresários e ao Estado empresarial..."'.

O empobrecimento das classes trabalhadores fez emergir necessidades de saúde que o Estado não tinha condições de prover. Cresceram em número as instituições previdenciárias e com elas, as desigualdades nos atendimentos e coberturas entre as diversas categorias profissionais, proporcionadas pelos seus próprios Institutos de Aposentadoria e Pensão (IAPs) ${ }^{6}$. A desigualdade social que se expressa na posse desigual do objeto e dos meios de trabalho e nas diferentes distribuições da riqueza social advinda do trabalho na maneira capitalista de produzir, manifesta-se também no acesso diferenciado aos serviços de assistência médica.

Em 1937, porém, num golpe de estado, Getúlio Vargas instaurou um governo totalitário nos moldes dos regimes fortes que já existiram na Itália e Alemanha. No Estado-Novo (1937-1945) o poder central passou a servir como intermediário nas negociações sobre política econômica, dando ênfase nas ações planificadoras e regulamentadoras. A regulamentação do trabalho e a política paternalista para com as classes operárias destinavam-se, primariamente, ao alívio das tensões sociais fruto da luta de classes, ainda que a acumulação do capital fosse sempre favorecida ${ }^{6.9}$.

As atividades previdenciárias continuavam a ser desenvolvidas pelas CAPs no âmbito privado e pelos IAPs no âmbito estatal. Sua unificação não foi possível senão em 1966, como já foi dito, ainda que o próprio governo Vargas a houvesse proposto antes da deposição. Opunham-se a ela os beneficiários dos diferentes institutos que, gozando de coberturas previdenciárias diferenciadas, temiam um nivelamento por baixo. Para chegar à unificação, a legislação do trabalho passou pela Consolidação das Leis do Trabalho de 1943, pela unificação das Caixas dos Ferroviários em 1953 e pela Lei Orgânica da Previdência Social de 1960, esta uniformização dos benefícios e serviços prestados pelos diversos IAPs'.

A derrota dos regimes totalitários no fim da segunda Guerra e o agravamento da crise econômica e política brasileira resultaram na queda de Vargas em $1945^{6}$. O discurso liberal da burguesia foi então substituído por outro, popular e desenvolvimentista que, embora preservasse os direitos da burguesia, lhe tirou a liderança política, que passou para as mãos do Estado ${ }^{3}$.

O desenvolvimento industrial foi reaquecido, com consequente melhora dos salários e a reativação da legislação trabalhista que fora gradativamente suspensa durante os anos da ditadura. Como consequiência da oposição dessas forças, surgiu novamente a inflação e, para contê-la, instaurou-se uma nova política 
anti-inflacionária, com o congelamento dos salários e do crédito. A contençāo salarial manifestou-se no descontentamento popular que reconduziu Getúlio Vargas à Presidência da República nas eleições diretas de 1950. A partir desta data, observa-se o período denominado Populismo. As lideranças políticas que se sucederam já não conseguiam uma oposição hegemônica, de forma que precisavam do apoio popular para legitimar seu poder. $\mathrm{O}$ " clientelismo" foi prática frequente para conseguir a adesão da massa populars.

As pressões sindicais levaram o Populismo a hipertrofiar em volume a assistência médica dos vários institutos de previdência social. Mutiplicaram-se os órgãos e cargos, já que cada um dos institutos funcionava com determinada clientela política, reduto eleitoral deste ou daquele deputado ${ }^{6}$.

Os anos 50 corresponderam a uma segunda etapa de industrialização em que os bens de consumo foram substituidos por bens de capital. Os maciços investimentos que a indústria necessitou para implementar tal mudança foram conseguidos no exterior. A entrada do capital estrangeiro foi combatida pelos nacionalistas e defendida pelos desenvolvimentistas, contradição que se agudizou e culminou com o suidídio de Vargas em 1954'.

O governo nacional-desenvolvimentista de Juscelino Kubitschek (1955 a 1960) pareceu conciliar essas posições antagônicas. No Plano de Metas de 1955, o Brasil definiu-se pela industrialização de bens de consumo duráveis e a produção industrial sobrepujou a agrícola pela primeira vez. "Emerge nitidamente $o$ domínio da burguesia industrial e seus interesses de expansão vão marcar a história a partir daí, definitivamente"'. No plano da Saúde Pública, esta vinha, desde 1942, assimilando o padrão norte-americano, com ênfase na educação sanitarista.

A hegemonia da burguesia industrial levou a interferências cada vez maiores nas relações capital-trabalho quando passou a pressionar o Estado por uma assistência médico-previdenciária para os industriários. A baixa eficácia desses serviços levou os empresários a constituir seus próprios serviços médicos, germe da "medicina de grupo" de hoje. No setor privado crescia a influência da medicina liberal., de caráter curativo, visando as camadas mais favorecidas da população $0^{6.7}$.

O novo surto inflacionário do início dos anos 60 precipitou a renúncia de Jânio Quadros e levou a um novo enfrentamento dos diferentes grupos da sociedade pela repartição do excedente social. A ditadura militar, a partir de 1964, trouxe consigo uma nova política para conter a inflação e que configurou a dependência do desenvolvimento interno ao capital estrangeiro. A rotatividade da mão-deobra, o aumento da carga horária de trabalho, constatável na prática, e a queda do poder aquisitivo das classes trabalhadoras levaram a intensa concentração de renda entre 1960 e $1970^{\circ}$.

Com o novo governo forte foram esquecidas as intenções descentralizadoras, regionalizadoras e participativas que se prenunciavam no início da década de 60. Em 1966 unificaram-se todos os Institutos de Previdência no Instituto Nacional de Previdência Social (INPS). No mesmo ano, criou-se o Fundo de Garantia pelo Tempo de Serviço (FGTS).

O governo já havia dado mostras de sua opção pelo capital quando asse- 
gurou benefícios previdenciários apenas aos trabalhadores regulados pela Consolidação das Leis do Trabalho, isto é, somente para aqueles que desempenhavam funções reconhecidas e reguladas pelo poder estatal. Desta forma, a Lei Orgânica da Previdência Social, de 1960, deixou à margem os trabalhadores rurais, os profissionais autônomos e as empregadas domésticas, grupos pouco estruturados em função de sua fragmentação e dispersão e que não conseguiam exercer pressão política a ponto de serem levados em conta nas políticas sociais produzidas pelo poder estatal'.

Os anos 60 vieram encerrar um ciclo de acumulação e iniciar outro, desta vez com importante participação do capital internacional. Até então, para assegurar a acumulação, a força de trabalho tivera que ser reproduzida intensamente. Com o desenvolver da tecnologia já não se necessitava de tão grande quantidade de mão-de-obra e nem era possível recrutá-la no exército de reserva sem especialização que gravita perifericamente ao sistema. O grau de urbanização de então já não comportava a família extensa e os filhos haviam perdido seu valor econômico.

Em 1970, com o objetivo de repassar aos trabalhadores parte dos lucros obtidos pelo sistema ecônomico com um todo, foi inaugurado Programa de Integração Social na Empresa (PIS). Em 1971, a criação do PRORURAL estendeu aos trabalhadores rurais os benefícios previdenciários que lhes haviam sido negados até então, quer pela falta de leis que os beneficiassem, quer pela ausência dos meios materiais para implementar essas leis. Esses mesmos benefícios passaram a atingir as empregadas domésticas em $1972 \mathrm{e}$ os trabalhadores autônomos em 1973. Essa evolução legislativa culminou em 1974, com a criação do Ministério da Previdência e Assistência Social ${ }^{6}$.

A assistência à saúde neste período se desenvolveu segundo um "modelo estatista privatizante, que vai centrar na reparação da força de trabalho, através das instituições criadas, todo seu potencial"'. Em 1972 tentou-se uma alteração nesse panorama, quando se determinou que a assistência médica deveria ser prestada prioritariamente nos serviços próprios do INPS e por outros órgãos, apenas quando esgotada sua capacidade de atendimento. Esta proposta foi invalidada dois anos mais tarde pelo Plano de Pronta Ação da Previdência Social, que voltou a se valer intensamente da rede privada demostrando, nesse sentido, a força das pressões das instituiçōes e grupos médicos de caráter privado ${ }^{6}$.

Tanto a privatização dos serviços como o aumento da demanda por parte da clientela e as despesas com acidentes de trabalho mantinham o INPS em permanente crise financeira. Neste contexto elaborou-se o II Plano Decenal de Desenvolvimento-PND (1975-1979) para enfrentar a crise social que se avolumava.

Surgindo o Goveno Geisel, época do "milagre brasileiro" o II PND enfatiza a necessidade do crescimento econômico, que seria obtido pelo controle da inflação, pelo equilíbrio da balança de pagamentos e pela estabilidade política, o que resultaria em melhores condições de vida para a população. Nessa mesma época foi criado o Ministério da Previdência e Assistência Social, para garantir o atendimento médico individual à população previdenciária, como resultado das pressões populares por cuidados médicos. Pode-se notar uma maior separação 
entre as atividades assistenciais curativas e aquelas ditas de saúde pública, que ficaram ao cargo do Ministério da Saúde.

Em 1980, surgiu o Programa Nacional de Serviços Básicos de Saúde (PREVSAÚDE) com uma proposta de expansão da cobertura dos serviços previdenciários através da otimização da utilização dos serviços de saúde e recursos já existentes, tendo como alvo principal as populações rurais e das periferias das cidades. Esta proposta, que enfatizava o cuidado primário e o estabelecimento de um sistema de referência que interligaria as diferentes instituições numa rede de complexibilidade escalonada, nunca chegou a ser implementada.

Também na década de 80 , no contexto da Reforma Sanitária que se iniciava e que buscava a redefinição do papel do setor público nos serviços de assistência à saúde, preconizou-se efetivamente um novo modelo assistencial, com a proposta de regionalização, hierarquização e integração dos referidos serviços. No Estado de São Paulo, esta proposta de inovação corporificou-se com a implantação do Plano de Ações Integradas de Saúde (AIS) através da reunião de várias agências prestadoras de serviços de saúde, subordinadas a nível regional à decisão e administração de recursos dos Escritórios Regionais de Saúde - ERSAs. Estes teriam como responsabilidadem entre outras, a de desenvolver os programas emanadas do Ministério da Saúde.

Em 21 de maio de 1987, comprometeram-se num acordo interinstitucional o Ministério da Previdência e Assistência Social (MPAS), com a participação do Instituto Nacional de Assistência Médica da Previdência Social (INAMPS) e a Secretaria do Estado da Saúde de São Paulo (SES) com a implantação do Sistema Unificado e Descentralizado de Saúde do Estado de São Paulo (SUDS). Esse convênio teve como objeto " a execução, pelo Estado de São Paulo, dos serviços de saúde a cargo do INAMPS, para efeito da integração desses serviços com os da SES e dos municípios do Sistema Unificado e Descentralizado de Saúde do Estado de São Paulo (SUDS)...", que se pretendia implementar pela unificação de todos os recursos físicos materiais e humanos, das diversas agências de saúde existentes no Estado de São Paulo?.

A nova Constituição promulgada em 1988 elevou a saúde à condição de um dos direitos da cidadania, além de dever do Estado. Entretanto, o acesso aos serviços de saúde, bem como a participação da população na gestão dos mesmos, paralelamente à questão do repasse financeiro aos municípios, ainda se colocam como questões a serem equacionadas.

\section{CONCLUSŌES}

A década de 90 que ora se inicia traz consigo alterações demográficas tais como a redução da fecundidade e o consequente envelhecimento populacional, o predomínio do grupo etário dos adultos jovens e a diminuição das faixas abaixo dos sete anos de idade. $O$ impacto dessas transformações sobre o perfil de morbi-mortalidade logo se fará sentir, colocando novas questões para o setor saúde. Pergunta-se como o projeto econômico neo-liberal inaugurado pelo governo Collor pretende responder a tais questões frente aos déficits sociais herdados dos 
ano 80 . Os postulados neo-liberais que o atual governo advoga, assim como sua política de controle inflacionário deixam antever uma redução do papel do Estado enquanto provedor direto dos serviços de saúde. Tal fato, aliado às pressões do setor privado, podem se constituir em ameaça as propostas descentralizadoras do SUS.

O intervencionismo estatal na proteção da força de trabalho envolve interesses de naturezas distintas, tanto econômica, quanto política, oriundas de demandas de classes sociais diversas. A mediação do Estado frente ao capital e ao trabalho, no dizer de OLIVEIRA4, busca hegemonia e consenso e o faz pela difunsão de uma ideologia política que esse mesmo autor traduz como sendo "um 'consentimento' particulamente organizado e dirigido das classes dominadas". Assim, ao assumir os interesses econômicos das classes dominadas, sob a forma de políticas sociais, preserva os interesses políticos da classe hegemônica.

Resta saber em que medida as classes trabalhadoras se constituirão em força política suficiente para que suas demandas sociais exerçam impacto sobre o projeto econômico do Estado, especialmente no que se refere aos gastos públicos e em particular, aos serviços de saúde.

OLIVEIRA, M.A. de C. Social and health policies in Brasil: an historical aproach. Rev. Esc. Enf. USP. v. 26, n. 1, p. 95-104, mar. 1992.

The author makes an historical approach of the brazilian social and health policies, trying to co-relate them to the changes of the mode of production of each historical cycle. She itends to clarify that social policies represent the state "administration" of conflicts between classes and that health policies express social inequalities, showed in a diferent acess to health utilities.

UNITERMS: Social policies. Health policies.

\section{REFERÊNCIAS BIBLIOGRÁFICAS}

1. ALBURQUERQUE, J.A.G. Da assistência à disciplina: .o programa de saúde comunitário. São Paulo, PROHASA, s.d. p. 1-129. mimeografado.

2. GERMANO, R.M. Educação e ideologia da enfermagem no Brasil. São Paulo, Cortez, 1983

3. GUIMARĀES, A.S.A. Estrutura e formação das classes sociais na Bahia.Novos Est. CEBRAP, São Paulo, n. 18, 57-69, 1987.

4. OliveirA, J.A. Política social, acumulaçāo e legitimidade. Rev. Adm. Publ., Rio de Janeiro, v. 18 , n. 20 , p. $110-26,1984$.

5. OLIVEIRA, M.A. de C. O planejamento da reproduçāo humana em uma sociedade de classes: estudo dialético das representaçōes de um conjunto de enfermeiras. Sāo Paulo, 1988, 243 p. Dissertação (Mestrado) - Escola de Enfermagem da Universidade de Sáo Paulo.

6. ROSSI, S.S. A constituição do sistema da saúde no Brasil Sảo Paulo, Departamento de Medicina Social da Faculdade de Ciências Médicas da Santa Casa. 1980. p. 1-43, 70-80.

7. SANTOS. W.G. Cidadania e justiça: a política social na ordem brasileira. Rio de Janeiro, Campus, 1979

8. SILVA, G.B. da. Enfermagem profissional: análise crítica. São Paulo. Cortez, 1986.

Rev. Esc. Enf. USP, v. 26, n. 1, p. 95-104, mar. 1992 
9. BRASIL. Leis. etc. Decreto $n^{2} 94.657$ de 20 de julho de 1987. Dispōe sobre os sistemas uniformizados e descentralizados de saúde nos Estados. Diário Oricial, Brasília, 21 jul. 1987. Seçāo I, p. 11503. 